Athens Journal of Business \& Economics -

Volume 7, Issue 3, July 2021-Pages 271-286

\title{
Transnational Entrepreneurship: A New Perspective on a Cooperative Approach towards Cross-border Entrepreneurship
}

\author{
By Christian Brandstetter ${ }^{*}$ Roman Kerres ${ }^{ \pm}$\& Carsten Hahn ${ }^{*}$
}

Cross-border cooperation in the early stages of a start-up might be one way of developing a sustainable and scalable business model for young enterprises. Thus, this paper is anchored at the intersection of the research areas of international Entrepreneurship and business model innovation. Its intention is to open up diverse perspectives for researchers in the field of cross-border Entrepreneurship. For this complex approach of cross-national cooperation, a theoretical framework with helpful knowledge has been developed. This work is considered relevant in view of the possible future developments in the fields of Innovation and Entrepreneurship. Global developments, such as the rapid growth of digitization, have a strong impact on the global economic situation as well as the field of Entrepreneurship (Kollmann et al. 2017). While on the one hand many people in Europe fear falling behind China and the USA when it comes to innovation, the associated potential for new, globally applicable business models is often neglected even though start-ups might have the courage to address them. However, they usually lack the resources and market access they need to implement their objectives. Therefore, this paper offers a new perspective on Transnational Entrepreneurship (TE) and demonstrates an approach for a cooperative possibility, how young companies can successfully discover cross-border market opportunities together with other start-ups and implement new business models successfully, providing a new perspective and first practical implications from action research-based pilot projects for Transnational Entrepreneurship. Furthermore, first practical implications were implemented through a university project in the challenging environment of resource constraints and cross-border communication.

Keywords: transnational, entrepreneurship, cooperation, business model, innovation

\section{Introduction}

In recent years, different patterns have emerged in the field of Entrepreneurship research. While an increasing number of business models had a digital background, the existence of information technology (IT) resources for start-ups seemed to stagnate. (Bundesministerium für Wirtschaft und Energie 2017) Even though the access to IT resources, whether in the autodidactic area or as an acquirable market-traded resource, has been considerably simplified in

\footnotetext{
"Research Associate, University of Applied Sciences Karlsruhe, Germany.

${ }^{ \pm}$Research Associate, University of Applied Sciences Karlsruhe, Germany.

"Professor, University of Applied Sciences Karlsruhe, Germany.
} 
recent years, there is an increasing proportion of skilled workers from abroad in start-ups (Bitkom 2019). Moreover, the autodidactic acquisition of such skills takes an enormous amount of time; time that founders usually do not have. This may be one of the reasons why more and more development capacity is being sought abroad. The number of services in the IT sector has also grown strongly in recent years in the context of start-ups. However, these service relationships often do not deliver the desired output. Many start-ups fail to realize their digital opportunities. Especially in the scaling phase of a business model, which is needed by many digitally driven companies to generate a critical mass of users for their product, these IT resources can become vital (Kollmann 2019). Often service relationships are already being sought with developers around the world, for example India. One hopes for quick pragmatic and above all cheap solutions. However, these cooperations often fail due to various obstacles, not least cultural differences, communication obstacles and different expectations (Bitkom 2019). On the other hand, for many companies from outside Europe, Germany offers a strong and central and large market in the heart of Europe and is therefore often the first point of contact for international start-ups. But even these companies often have a number of similar obstacles that they face. For example, registering a business or establishing a business address is already a difficult undertaking. In general, not all companies are directly open to foreign products and services, which is why there are additional hurdles to successful expansion in the German market (Sternad et al. 2018) In the following, an approach is described that could help to jointly exploit the disadvantages described to your advantage. Therefore, in the first part, the existing literature in the field of Transnational Entrepreneurship will be examined more closely (Bailetti 2018, Gangadhar and Manohar 2015).

\section{Literature Review}

This chapter aims to provide a short overview regarding the differing research streams in cross-border Entrepreneurship and the underlying different perspectives for the concept of Transnational Entrepreneurship in the literature.

\section{The Term Transnational}

The prefix trans stems from Latin. In the context of Transnationalism, it means across or beyond. The term natio is based in the latin language as well and refers to a nation or state. As a result, trans-national describes processes and characteristics that take place across national borders. These are regarded as intensive and complex. The term transnational contains subnational, national and international components. The notion is used in different areas such as economy, sociology, cultural studies, historiography and many more (Gangadhar and Manohar 2015).

The terms international, global and transnational are often used synonymously for extending across national borders. In a way, one can say that the term transnational resembles a further development of the other terms or describes kind 
of a vision for the future. It is usually referred to as an intensive relationship between partners, which seems to make the concept of nations with borders almost redundant (Gangadhar and Manohar 2015). Thus, the term transnational refers to complex processes beyond national borders, which are strongly rooted in the individual nations, without identifying a single nation as point of origin.

\section{Transnationalism}

Transnationalism is a continuously growing social phenomenon (Gangadhar and Manohar 2015). The fact that the phenomenon is developing further, and the weak boundaries to other concepts like internationalism, supranationalism, immigration and assimilation lead to different research directions, studies and various definitions of the term. An important distinction from the concepts of internationalism and supranationalism is that transnationalism, in contrast to these two concepts, refers to non-state actors (UNESCO 2017). While some researchers argue that Transnationalism has existed for ages, a recognizable pattern was only established because of global factors during globalization like reduced transportation and communication costs. Portes et al. are describing the technological development as one of the main drivers for the establishment of Transnationalism. The existence of networks between the countries of origin and settlement as well as in each of them is another necessary condition (Kollmann et al. 2017). These technological developments simplified this process noticeably, as communication technologies have developed. Despite the numerous ongoing debates facing the nature of the concept and the newness of the concept researchers recognized a growing consensus of the social ties between the societies of origin and settlement. (Engbersen et al. 2014) According to Wenhong, Tan and Portes, Transnationalism from a theoretical perspective is different from conventional theories, in which immigration is displayed as a one-way linear process. In Transnationalism migrants rather maintain intensive relationships to their home country (Brzozowski et al. 2017, Ojo 2017, Wenhong and Tan 2009).

While the connection to the home country was previously regarded as irrelevant, these very structures proved to be a competitive advantage in transnational activities (Lundberg and Rehnfors 2018, Wenhong and Tan 2009). Transnationalism is considered a novelty, especially regarding classical immigration, as it includes networks and continuous relationships to the home country (Gangadhar and Manohar 2015, Zapata-Barrero and Rezaei 2020). Consequently, Transnationalism describes a comparatively close cross-border exchange to a certain extent, the concept strives for a holistic system that regards state borders as obsolete.

\section{Entrepreneurship as a Field of Research}

Entrepreneurship as a field of research has been attracting increased attention for years, both theoretically and practically. This gets visible by observing the number of publications in various research areas, as well as the increasing establishment of chairs and contents in universities. Furthermore, policy makers 
show great interest in the further development of this area. Additionally, Entrepreneurship is regarded as an important economic element and a major source of new employment (Kollmann et al. 2017). Its diversity of research areas and the tremendous number of authors from a rising number of disciplines might be one reason for the non-existence of a generally valid definition. For the further course and the later development of a definition for the concept of Transnational Entrepreneurship, a separate definition is derived from the preceding definitions and core contents.

Considering the different existing definitions, some core contents of Entrepreneurship can be outlined. It should be noted that not every definition sets the same priorities. However, there are repeated occurrences of these elements including the identification and exploitation of entrepreneurial opportunities, innovation and novelty, resource constraints, risks and uncertainties, value creation, problem solving, customer orientation and individual and dynamic processes (Fritsch 2016, Fueglistaller et al. 2016, Schumpeter et al. 1912, Scott and Venkatarman 2000, Stevenson 2006). For the further course and the later development of a definition for the new perspective on Transnational Entrepreneurship, an interpretation for Entrepreneurship will be introduced. As a result, in the context of this paper Entrepreneurship is referred to as a proactive, opportunity-driven and customer-orientated process of identifying market opportunities, developing business ideas and implementing them, usually accompanied by uncertainty, resource constraints and individual influences.

\section{Start-ups and their Motivation to Access Foreign Markets}

Technology-oriented start-ups in particular have an increased urge to internationalize their activities at an early stage and often seek to expand in an early-stage. In such situations the domestic market may have limited size and potential for their business model. In such situations, the early internationalization can be an important success factor (Sternad et al. 2018). Studies show that startups that carry out internationalization do not fail more often than Startups that stay on the local market (Sleuwegen and Onkelinx 2014). Furthermore, there are various factors fueling the internationalization of start-ups. These include external factors such as industry characteristics, such as highly internationalized or technologized industries, or market factors, such as limited opportunities or size. Internal factors such as an international composition of the founders' team and related know-how or experience in international business as well as a large international network can also favor this orientation. Besides the chances for a higher turnover there can occur several other positive effects for start-ups in the context of internationalization. Engaging in foreign countries may gain access to new resources, collaboration partners and can strengthen the ability to innovate within the company (Sternad et al. 2018). However, cooperation is widely regarded as helpful for young companies in view of scarce resources and lack of skills in various areas (Becker et al. 2011).

Cooperation within start-ups indeed is described as helpful for innovation regrading research and development $(\mathrm{R} \& \mathrm{D})$ and the innovation business models in 
the literature (Becker 2012, Egge and Müller 2014, Herstatt et al. 2007, Sternad et al. 2018). The challenges associated with internationalization for start-ups in connection with their characteristics and the need to cooperate enables them as an interesting potential target group for Transnational Entrepreneurship. Due to their characteristics, these companies could have an enhanced potential to benefit from Transnational Entrepreneurship.

\section{Previous Research on Transnational Entrepreneurship and Transnational Entrepreneurs}

Table 1. Definitions of Transnational Entrepreneurs and Transnational Entrepreneurship in the Literature (own presentation)

\begin{tabular}{|c|c|}
\hline Transnational Entrepreneur & Transnational Entrepreneurship \\
\hline $\begin{array}{l}\text { (1) "[...] self-employed immigrants whose } \\
\text { business activities require frequent travel } \\
\text { abroad and who depend for the success of } \\
\text { their firms on their contacts and associates in } \\
\text { another country, primarily their country of } \\
\text { origin"(Portes et al. 2002). }\end{array}$ & $\begin{array}{l}\text { (5) "[...] is a multi-faceted process, in } \\
\text { which immigrant entrepreneurs discover } \\
\text { and enact business opportunities across } \\
\text { national borders"(Drori et al. 2009). }\end{array}$ \\
\hline $\begin{array}{l}\text { (2) "Transnational entrepreneurs are } \\
\text { immigrant entrepreneurs who perform } \\
\text { border crossing business activities across } \\
\text { national borders"(Wenhong and Tan 2009). }\end{array}$ & $\begin{array}{l}\text { (6) "[...] implies immigrant business } \\
\text { engagement not only in the host country, } \\
\text { but also in the country of } \\
\text { origin"(Brzozowski et al. 2014). }\end{array}$ \\
\hline $\begin{array}{l}\text { (3) "[...] transnational entrepreneurs are } \\
\text { individuals who migrate from one country to } \\
\text { another, concurrently maintaining business- } \\
\text { related linkages with their countries of origin } \\
\text { [...]"(Drori et al. 2010). }\end{array}$ & $\begin{array}{l}\text { (7) "[...] the process of transnational } \\
\text { entrepreneurship involves entrepreneurial } \\
\text { activities that are carried out in a cross- } \\
\text { national context and initiated by actors } \\
\text { who are embedded in at least two different } \\
\text { social and economic arenas" (Wenhong } \\
\text { and Tan 2009). }\end{array}$ \\
\hline $\begin{array}{l}\text { (4) "Transnational Entrepreneurs are } \\
\text { individuals that have ties to both existing } \\
\text { organizations in industry and geographic } \\
\text { regions distant from these organizations } \\
\text { might have the ability to translate these } \\
\text { positions into particularly promising } \\
\text { entrepreneurial opportunities" (Flores et al. } \\
\text { 2010). }\end{array}$ & $\begin{array}{l}\text { (8) "[...] individuals who migrate to } \\
\text { another country while maintaining } \\
\text { business linkages with both the country of } \\
\text { origin and the country of } \\
\text { destination"(Santamaria-Alvarez et al. } \\
\text { 2018). }\end{array}$ \\
\hline
\end{tabular}

Transnational Entrepreneurship as a field of research is relatively recent and has gained increased attention in the literature in the past two to three decades (Drori et al. 2009). Gangadhar and Manohar (2015) argue that the view in which an entrepreneur only uses entrepreneurial opportunities in a single institutional environment is obsolete. The main reasons in for this are factors such as low transport and communication costs, the removal of trade barriers and the increasing individualized lifestyles. At the same time, these are drivers of transnationalism (Gangadhar and Manohar 2015). Transnational Entrepreneurs might have the ability to create greater value and act more effectively than their counterparts 
operating in a single country (Flores et al. 2010). These result from the individual abilities of the Transnational Entrepreneurs. Which include the possibility to use resources from two different areas, intercultural understanding and knowledge as well as a large personal network (Gangadhar and Manohar 2015) In summary it can be said that, the literature regarding Transnational Entrepreneurship, focuses primarily on the individual, so far. The Transnational Entrepreneur, who is often referred to as an immigrant and his individual capabilities, resources and environment, is mainly the center of attention in research (Gangadhar and Manohar 2015). In 2018, Bailetti published a definition with a new perspective, after having analyzed many other definitions. He focuses on the transnational entrepreneurs enterprise, rather than the entrepreneur (Bailetti 2018). In summary, it can be said that research is limited primarily to the intersections of the themes of immigration, ethnic Entrepreneurship and transnationalism. The research emphasizes on the links between individuals and their countries of origin and the integration of immigrants into their countries of destination (Gangadhar and Manohar 2015). Recently, the company in the transnational context was analyzed more closely in the literature (Bailetti 2018), due to the individual Entrepreneur being at the center of attention so far. Most publications derive from human-centered research directions like sociology and its related disciplines. This changes within the new approach of this work. The focus is on the entrepreneurial component including business model emphasis.

\section{Business Model Innovation and Motivation}

Figure 1. Business Model Canvas

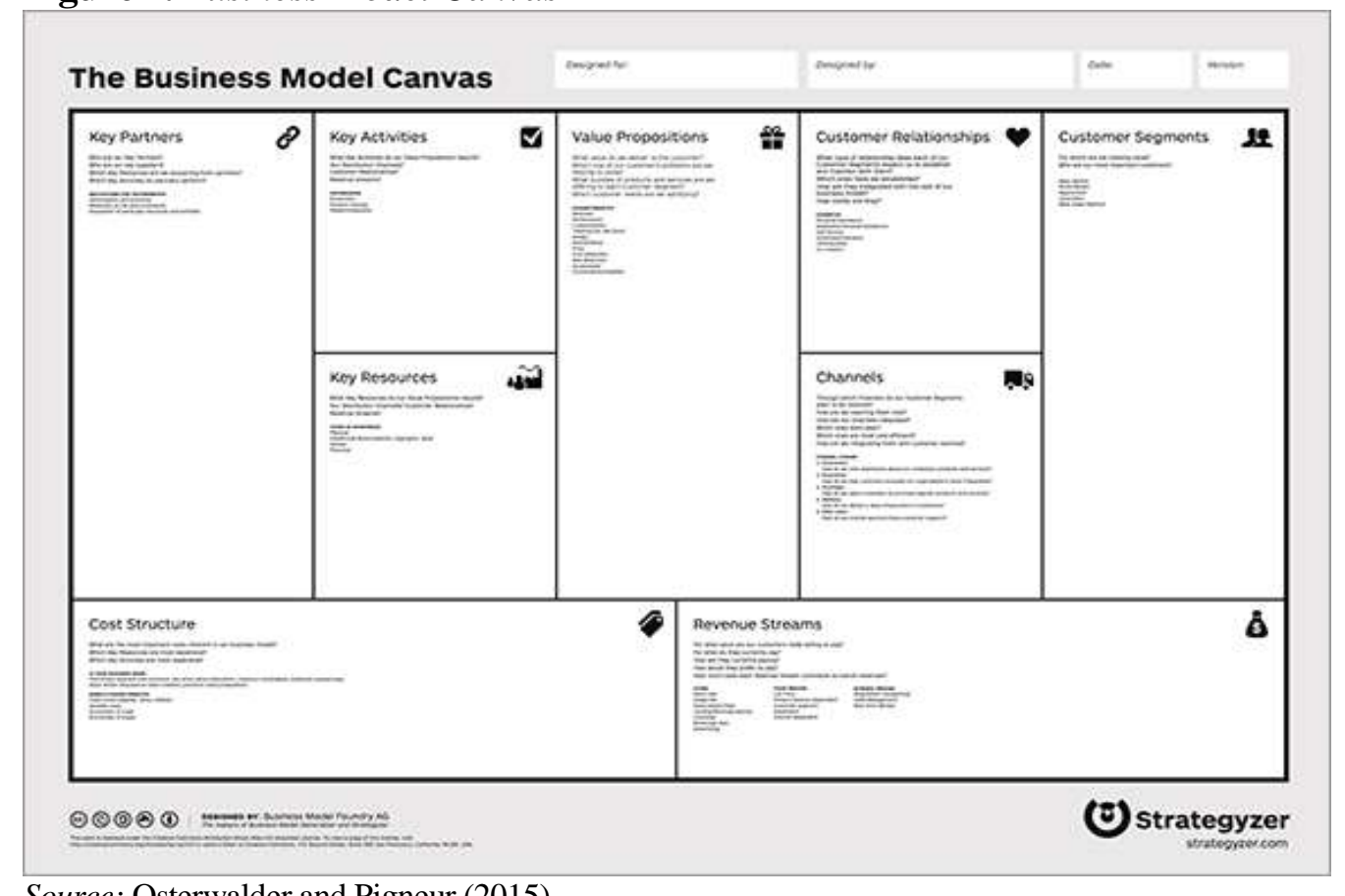

Source: Osterwalder and Pigneur (2015). 
There are several ways to illustrate a business model. The Business Model Canvas (BMC) by Osterwalder and Pigneur is an appropriate tool to illustrate the initial situation and the business models of the two young companies (Osterwalder et al. 2015, Osterwalder and Pigneur 2013). The value proposition of the business model is expressed in coloration in the middle of the BMC. This describes the value for the customer and is therefore a central component of the business model. A convincing value proposition adapted to the customer is created by a complete business model. It is therefore the basic motivation to optimize the business model on both sides (Osterwalder et al. 2015). The six fields to the right and left of the value proposition are especially important for this work. On the left-hand side key partners, key resources and key activities are displayed. On the other side, there are customer relationships, channels and customer segments. These two groups of fields thus can be roughly divided into the two areas of resource-related (left) and market-related (right hand side). Following this idea, the motivation for Transnational Entrepreneurship has two main causes.

- resource-based-motivation (e.g., to gather competences or partners, that are not sufficiently available in the home country).

- market-based-motivation (e.g., to gain market access or access to specific channels or customer segments within a market).

As a result, one possibility for bringing partners together could be to have both motivations represented in the process.

\section{Methodology}

Summarizing the literature to date, the entrepreneurial activities of immigrant individuals have been examined within the fairly young researched area of Transnational Entrepreneurship (Drori et al. 2009, Gangadhar and Manohar 2015). The study of literature has confirmed that many start-ups, especially for reasons of resource constraints, seek and appreciate cooperation (Becker 2012). An urge for internationalization can be observed as well. Particularly, in the development and activities on new markets, local and internationally, the cooperation with partners is regarded as meaningful instrument and can increase the chances of success of the project. Digitally affine companies are often the focus of these studies. They are attributed with a strong urge for internationalization (Kollmann et al. 2017, Sternad et al. 2018).

Action Research is used as the main research methodology for this research project. Action research has the objective to contribute to the practical concerns of people in an immediate problematic situation and to the goals of social science by joint collaboration within a reciprocal acceptable ethical framing (Rapoport 1970). This methodology has two main objectives. It aims to contribute to both practice and theory. The origin of action research stems from Kurt Lewin (Adelman 1993). There are five principles that have to be noted using this method (Davison et al., 2004), including the principles of (1) researcher client-agreement, (2) cyclical 
process model, (3) theory, (4) change trough action and (5) learning trough reflection.

These principles are usually applied using in an iterative process model which starts with the diagnosis of a practical problem which shall be solved. Figure 2 illustrates the action research cyclic model in which consists of five steps by Susman and Everett (1978).

Live-Labs are validation environments that are used by researchers to investigate processes, methods and tools under realistic conditions (Albers et al. 2016). For the intital application in the field of Transnational Entrepreneurship and the first integration of the theoretical concept this method is useful and offers possibilities for a fast adaptation of the assumptions and learning.

Figure 2. Action Research Cyclical Process Model

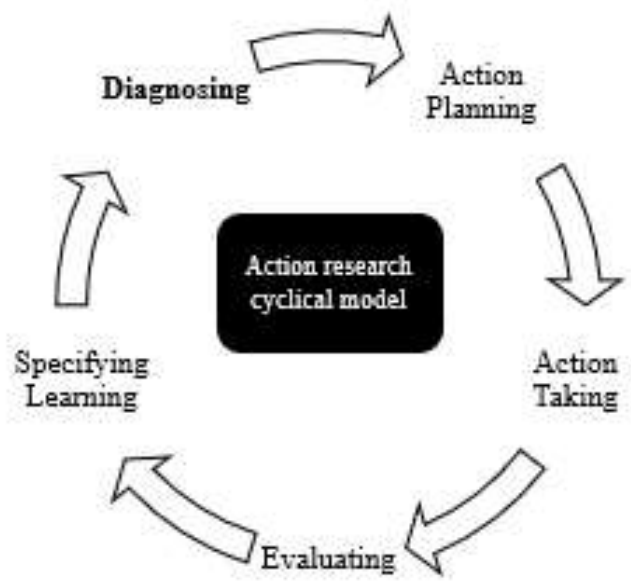

Source: Susman and Evered (1978).

In the study course start-up-semester, students of the University of Applied Sciences Karlsruhe are working jointly with students from other faculties for one semester on a real entrepreneurial problem as part of their regular courses. The students learn to think and act like an entrepreneur for one semester. The aim is to confront students with entrepreneurial tasks and challenges (G-Lab One 2020). It additionally offers the valuable opportunity of a living experimental environment in the research field of entrepreneurship which was used during this project. Summarizing, this project focuses on giving a new perspective on Transnational Entrepreneurship and their first practical implications by referring to the following questions:

1. Which dimensions and focal points should be considered for a new perspective on Transnational Entrepreneurship oriented towards business model innovating start-ups?

2. How can first practical experiences be generated by applying them and what do these experiences indicate? 


\section{Results}

\section{A New Perspective on Transnational Entrepreneurship}

Global developments and growing phenomenon like transnationalism are having impact on business models, which are becoming increasingly international. In order to take advantage of these opportunities, a new approach has been developed to investigate this process. In practice, various models have already been successfully tested at the university. This initial paper is a basic work, which offers possibilities for further research directions and profound research, as well as for practical projects. In addition to the validation of hypotheses in the context of this work, interesting starting points are offered. One possibility would be to accompany the transnational start-up-semester project.

One of the key results is the development of a new perspective on Transnational Entrepreneurship: While conventional research in this field has focused on the origins of individual entrepreneurs, the presented approach emphasizes the area of business model innovation and Entrepreneurship. Therefore, a new definition is presented below. A definition is a precise exposition of a term, by breaking it down and explaining its contents. The definition is important in order to be able to convey a topic quickly and uniformly (Rickert 1929). In this way, it can be defined whether or not a certain activity belongs to the defined process. It can be viewed critically that a definition can entail restrictions. In the following, the developed interpretations including the term (1) transnational, (2) transnationalism and (3) Entrepreneurship are summarized. They form the basis for the new perspective on (4) Transnational Entrepreneurship.

(1) The term transnational describes complex processes beyond national borders, which are strongly rooted in the individual nations, without identifying with a single nation as point of origin.

(2) Transnationalism describes a comparatively close cross-border exchange. To a certain extent, the concept strives for a holistic system that regards state borders as obsolete.

(3) Entrepreneurship is a proactive, opportunity-driven and customerorientated process of identifying market opportunities, developing business ideas and implementing them, usually accompanied by uncertainty, resource constraints and individual influences.

Based on these derivations, the following definition for the concept of Transnational Entrepreneurship emerges:

Transnational Entrepreneurship refers to complex, cross-border, cooperative processes of identifying market opportunities, developing business ideas and their implementation, which are accompanied by uncertainty and individual influences 


\section{Initial Practical Approaches}

In the following, the first application of the developed approach will be examined as an example for Transnational Entrepreneurship in detail. These are outlined using the action research methodology and the corresponding cycle model.

\section{Diagnosing the Problem}

The initial situation is illustrated using two start-ups and a short description of their business models and motives from India (A) and Germany (B). Transnational partner A (TPA) with business model A (BMA) from India offers a software solution for predictive analytics based on sensor-based Internet of Things (IoT). The technologies TPA provides a solution that is flexible applicable. This means it is helpful for companies to reduce downtimes of machines, to optimize maintenance and reduce the energy consumption. The solution collects data with the help of various sensors. A dashboard including different and many optional widgets offer an overall view of production, machines, fleet and assets. Recommended actions to avoid downtimes or production loss will be provided based on the collected data of the sensor system. An algorithm detects mechanical changes reflected by electrical signals. So that downtimes or necessary machine checks can be predicted in an early stage and continued along with recommended actions to avoid failure. It is a proven solution with more than four thousand successful installations, established partners and customers throughout the Indian market. The company has identified the German market as valuable for itself and would like to approach small and medium-sized companies in the German market to sell its software solution. Germany is an interesting market because Germany and the surrounding part of Western Europe is predicted to see major growth in the area of IoT-based technologies. Growth potential is forecasted especially in mechanical and plant engineering. The start-up is facing difficulties during entering the market, as German companies are often very traditional and are reluctant to trust in resources from abroad, especially when it comes to information technology. The resulting challenge is to enter the German market in the area of plant-engineering and manufacturing to sell IoT-based predictive maintenance software.

Transnational partner B (TPB) has a business model B (BMB). It could have its core competencies in the field of hardware technology and might be working on special sensor solutions for the acquisition of data that machines provide and which are becoming increasingly important today (see Figure 3). The objective is to make the usefulness of this data available and transparent for medium-sized companies in Germany. The start-up, which was represented by a student group could generate data better and more effectively than other competitors. However, the interpretation and preparation of this data is a problem, as it usually must be tailored to the customer's specific needs, since not all machine owners need and want the same data. In addition, the founders are particularly strong in the fields of sensor technology and electronics, while information technology and competencies in the area of networking technical systems are rather weakly represented in the 
team. The challenge of partner B was to understand customers and find out what is important to them. Improve the communication of one's own customer value and check whether it is available. Furthermore, resources are needed in the area of Information Technologies. Consequently, TPB has a resource-based motivation for Transnational Entrepreneurship and the related business model innovation.

The aim of the project was to evaluate the possibilities for TPA on the German market (B) and to work out which adjustments to the existing business model are necessary and how mutual benefits can be created here in cooperation with TPB.

Figure 3. Initial Situation and Problem Diagnosis

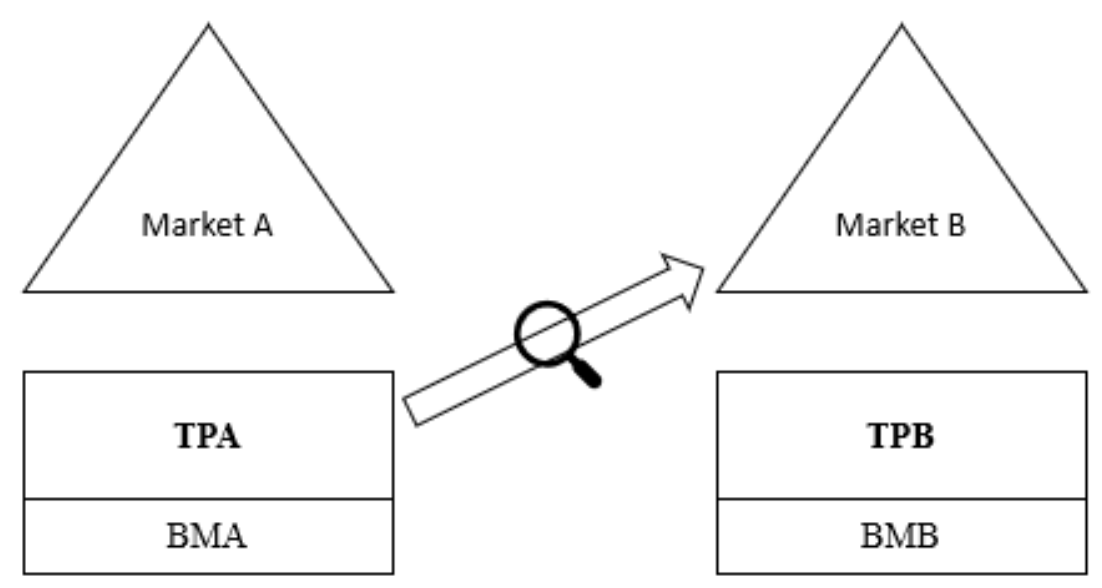

\section{$\underline{\text { Action Planning }}$}

As already mentioned, an existing concept, the start-up-semester was newly established on the German side with a special focus. In this way, an interdisciplinary team was put together to work out the diagnosed problem. A member of the team, who was serving as a coach as well, was stationed on site in Bangalore to improve communication and reduce cultural and language barriers. This should ensure that the project is focused on the contained component of the cooperative entrepreneurship approach.

\section{Action Taking}

In the course of this project, the first step was a fundamental analysis of the initial situation by the student team (Partner B). In this way, the applicability of $\mathrm{BM}-\mathrm{B}$ to market A was to be roughly assessed for the first time. The focus was on existing competitors and the analysis of potential target customers for $\mathrm{A}$ on the German market. The most valuable learning from this is that a market and customer analysis by the partner can bring great advantages for the other company. Based on this mutual analysis and the resulting overview, proposals for new sales strategies, access to potential valuable partners in the target market and interesting niche markets and business model adjustments can be developed. The resources of both partners can be integrated simultaneously. 


\section{Evaluating and Specifying Learning}

Due to the great interest in the research project and the start of the transnational start, further findings were gathered at a workshop in Bangalore, India to evaluate potential start-ups for Transnational Entrepreneurship. Together with one of the largest Indian incubators, the National Association of Software and Service Companies (NASSCOM) and the German-Indian start-up Exchange Program (GINSEP) supported by the Ministry of Economics, the research team from the University of Applied Sciences Karlsruhe conducted a workshop for Indian technology start-ups. Together, opportunities and challenges of the individual business models were evaluated with regard to an expansion into the German and European market. All start-ups had gone through an application process beforehand, as the demand was very high. Only a certain number of start-ups could be processed per coach in order to provide enough support for the individual teams. Thus, certain criteria were communicated in advance to make it more realistic for applicants to expand into the German market. Criteria such as a minimum number of employees of twenty, $\$ 100,000$ annual turnover and more than ten customers on the domestic market were considered prerequisites the will and motivation for market expansion into the German market was examined. During the workshop the participants assessed their own start-up based on five criteria and discussed this with other entrepreneurs and the coaches from Germany and India. The five criteria were market success in the Indian market, the financial strength of the company, expected cultural barriers in the German market with regard to the company's own business model, market knowledge of the German market and expected regulatory barriers to expansion. Figure 4 shows the collected answers of the ten participating companies.

Figure 4. Workshop Evaluation

\section{Workshop Evaluation}

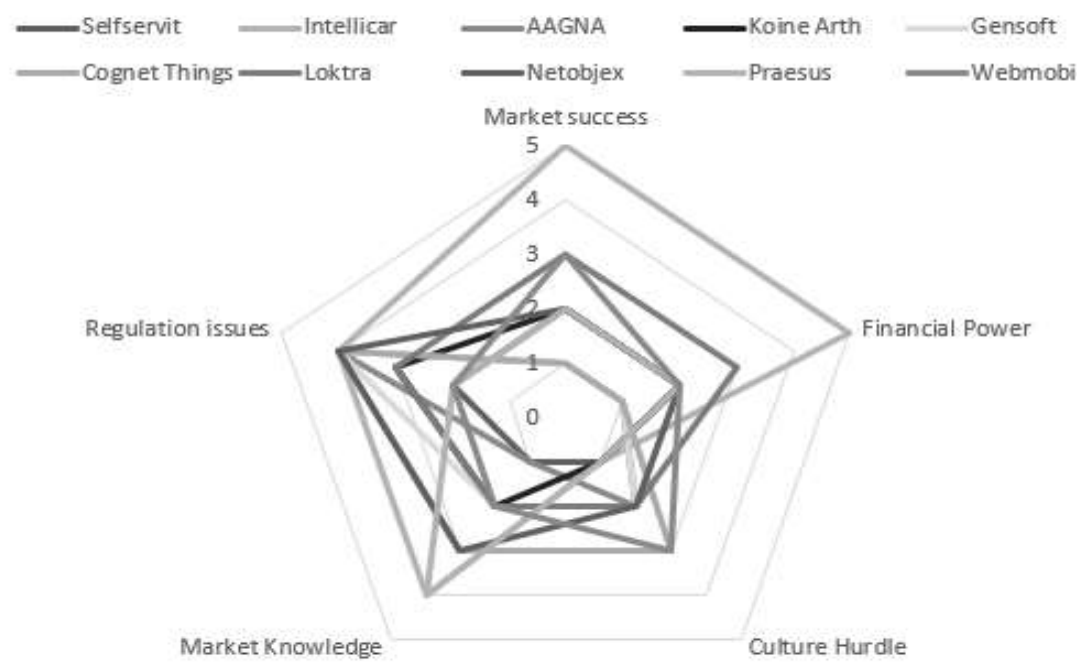

The evaluation of the workshop also shows that precisely these general hurdles are often underestimated. Market knowledge and associated risks, such as regulatory conditions, are often not considered sufficient. An initial investigation 
shows that a mere copy of the existing business model in the new market is not promising. Some of the biggest challenges are cultural differences and the perception of services from abroad. For example, medium-sized companies are often sensitive regarding information technology products and still may associate products from abroad with poor quality (Tödtmann 2018). Moreover, market niches that work in one market are either already occupied by other market players in other markets or do not exist at all. Therefore, a reorientation of the business model is necessary. It is therefore advisable, presumably, to unite both existing formally separate organizations, at least with regard to customer contact.

Consequently, the partner companies should place particular emphasis on using the complementary resources of their business models in such a way that an improved value proposition, adapted to the respective market, results with the highest benefit for the specific customer. This is illustrated in Figure 5 by the cooperative business model $C$. Simplified, the following scenario illustrates a joint cooperation as peer partners within the framework of Transnational Entrepreneurship.

Figure 5. Cooperative Business Model as Peer-Partners

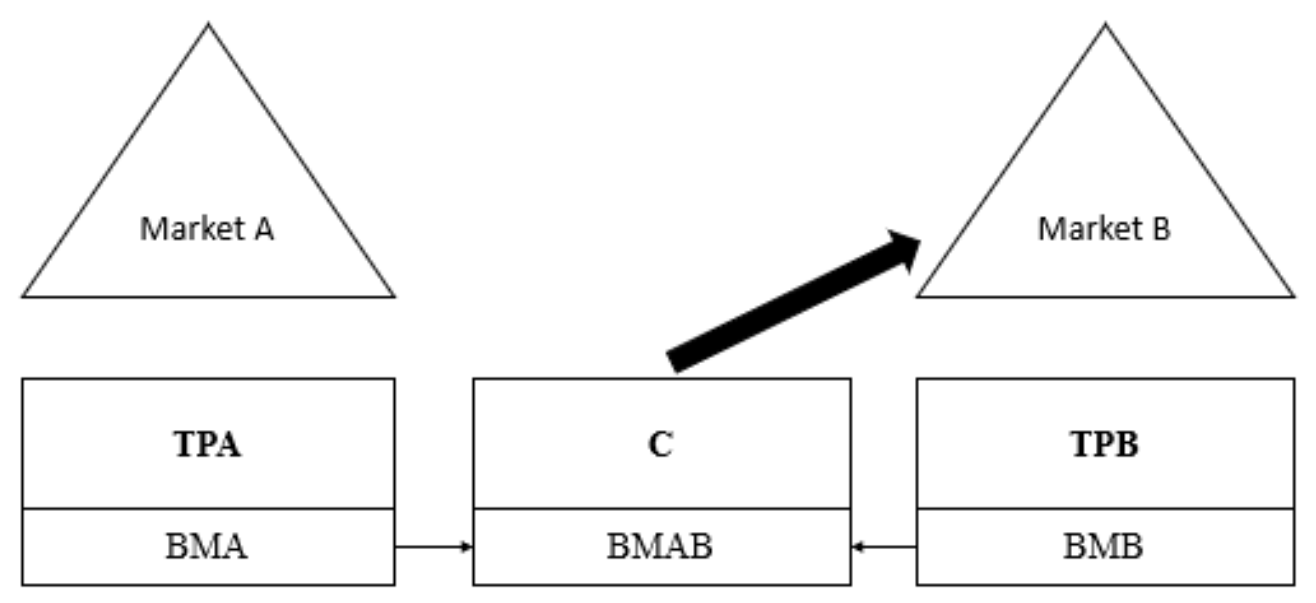

\section{Discussion and Limitations}

Within the framework of the research project some limitations have to be considered. This paper refers to a live lab, which is still in the test phase. Even if first results are not ambiguous, they still provide important insights for a positive implementation. Due to limited available resources for the university project the project is built up gradually and iteratively. Future research focus could, for example, be the design of joint business models. Further research topics result from the practical implementation of the concept. For long-term partnerships in the field of Transnational Entrepreneurship many more things have to be observed and considered. Especially the acquisition of suitable start-ups in both countries is an enormous challenge. In addition, there are further open questions as to how a 
legally binding cooperation can and should be concluded, if necessary. In addition, there are well-known challenges regarding international cooperation like communication and cultural dares. In the course of the paper it should be considered that especially the practical knowledge gained in the field will only be increasingly available in the future, if more pilot projects are going to be initiated, which can build up on the theoretical knowledge base gained.

With regard to the strong existing literature flow, which highlights increasingly migrated entrepreneurs and their connections and actions, this paper can be seen as a practical and business model related addition (Bailetti 2018, Gangadhar and Manohar 2015, Ojo 2017, Zapata-Barrero and Rezaei 2020). It is clear, however, that other disciplines are at the centre of attention here. It would be desirable to have more researchers to take up the subject from this perspective and thus also pay more attention to the respective business models.

\section{Conclusion}

In summary, most importantly this paper offers a new perspective on the research field of cross-border entrepreneurship. It focuses on the creation of a joint customer-oriented value proposition of two start-ups as peer partners. The methodology of the Business Model Canvas is used as the basis for the theoretical framework describing the innovative cooperation model of young companies. The development of a cooperative business model has been a core element of the action-based research approach, which unites various elements of the cooperation partners and thus creates valuable synergies. Furthermore, first practical insights were gained from the living lab and a subsequent workshop. These indicate that it is by far not enough to simply copy a business model in order to be successful in a new market across borders. A close cooperation as peer-partners and a cooperative adaption of the business models seems to be a possible success factor. However, the new perspective on Transnational Entrepreneurship is primarily intended to provide a basis for a number of further theoretical and applied research projects.

\section{References}

Adelman C (1993) Kurt Lewin and the origins of action research. Educational Action Research 1(1): 7-24.

Albers A, Walter N, Hahn C, Schröder J (2016) ProVIL - Produktentwicklung im virtuellen Ideenlabor. (ProVIL - Product development in the virtual idea lab). In R Stelzer (ed.), Entwerfen Entwickeln Erleben 2016 - Beiträge zur virtuellen Produktentwicklung und Konstruktionstechnik. Dresden: TUDpress.

Bailetti E (2018) Transnational entrepreneurship. Distinctive features and a new definition. Technology Innovation Management Review 8(9): 28-38.

Becker W (2012) Erfolgsfaktoren der Geschäftsmodelle junger Unternehmen. (Success factors of business models from young comapanies). Bamberg: Univ. Lehrstuhl für Betriebswirtschaftslehre insbes. Unternehmensführung und Controlling. 
Becker T, Dammer I, Loose A (2011) Netzwerkmanagement. (Network-management). Heidelberg: Springer.

Bitkom EV (Hg.) (2019) Bitkom Startup Report 2019. Retrieved from: https://bit.ly/3Ba8 wQC. [Accessed 7 September 2020.]

Brzozowski J, Cucculelli M, Surdej A (2014) Transnational ties and performance of immigrant entrepreneurs: the role of home-country conditions. Entrepreneurship \& Regional 26(7-8): 546-573.

Brzozowski J, Cucculelli M, Surdej A (2017) The determinants of transnational entrepreneurship and transnational ties' dynamics among immigrant entrepreneurs in ICT sector in Italy. International Migration 55(3): 105-125.

Bundesministerium für Wirtschaft und Energie (Hg.) (2017) Themenheft "Digitale Geschäftsmodelle". (Issue "Digital business models"). Frankfurt am Main: Zarbock $\mathrm{GmbH} \&$ Co. KG.

Davison R, Martinsons MG, Kock N (2004) Principles of canonical action research. Information Systems Journal 14(1): 65-86.

Drori I, Honig B, Wright M (2009) Transnational entrepreneurship. An emergent field of study. Entrepreneurship Theory and Practice 33(5): 1001-1022.

Drori I, Honig B, Ginsberg A (2010) Transnational \& immigrant entrepreneurship in a globalized world (2. Aufl.). Toronto: University of Toronto Press (Rotman-UTP Publishing).

Egge B, Müller D (2014) Kooperation Junger Technologieunternehmen mit Wettbewerbern: Der Einfluss von Vertragsvereinbarungen und Beziehungskapital auf den Kooperationserfolg. (Cooperation of young technology companies with competitors: the influence of contractual agreements and relationship capital on the success of cooperation). In A Walter (ed.), Case Studies on the Foundation and Development of Innovation-Oriented Companies: Influencing Factors and Theoretical Anchoring of Success. Berlin: Springer Gabler.

Engbersen G, Bakker L, Erdal M, Bivand BÖ (2014) Transnationalism in a comparative perspective: an introduction. $C M S 3(2): 255-260$.

Flores I, Young M, Tarter J (2010) The transnational entrepreneur: an initial overview of factors affecting international strategies. International Journal of Business Strategy 10(4): 207-223.

Fritsch M (2016) Entrepreneurship: Theorie, Empirie, Politik. (Entrepreneurship, Theory, Empiric, Politics). Berlin: Springer Gabler.

Fueglistaller U, Müller C, Müller S, Volery T (Hg.) (2016) Entrepreneurship. Modelle Umsetzung - Perspektiven: mit Fallbeispielen aus Deutschland, Österreich und der Schweiz (Entrepreneurship. Models - Implementation - Perspectives: with case studies from Germany, Austria and Switzerland (4. Aufl.). Berlin: Springer Gabler.

G-Lab One (2020) What we are doing. Retrieved from: https://g-lab.one/formate/. [Accessed 7 September 2020.]

Gangadhar N, Manohar BM (2015) Understanding transnational entrepreneurship. International Journal of Advances in Management and Economics 4(6): 52-67.

Herstatt C, Buse S, Napp JJ (2007) Cooperation in the early phases of the innovation process. Potentials for small and medium-sized enterprises. (Cooperation in the early phases of the innovation process. Potentials for small and medium-sized enterprises). Hamburg: RIS Hamburg.

Kollmann T (2019) E-Entrepreneurship: basics of starting a business in the digital economy. $7^{\text {th }}$ Edition. Berlin: Springer Gabler.

Kollmann T, Stöckmann C, Hensellek S, Kensbock J (2017) Deutscher start-up monitor 2017. (German start-up monitor 2017). Berlin: Bundesverband Deutsche Startups e.V. 
Lundberg H, Rehnfors A (2018) Transnational entrepreneurship: opportunity identification and venture creation. Journal of International Entrepreneurship 16(2): 150-175.

Ojo S (2017) Diasporas and transnational entrepreneurship in global contexts. Advances in business strategy and competitive advantage (ABSCA) book series. IGI Global.

Osterwalder A, Pigneur Y (2013) Business model generation: a handbook for visionaries, game changers, and challengers. Hoboken, New Jersey: Wiley \& Sons.

Osterwalder A, Pigneur Y, Bernada G, Smith A (2015) Value Proposition Design: Entwickeln Sie Produkte und Services, die Ihre Kunden wirklich wollen Die Fortsetzung des Bestsellers Business Model Generation. (Value proposition design: how to create products and services customers want). Frankfurt am Main: Campus Verlag.

Portes A, Guarnizo L, William JH (2002) Transnational entrepreneurs: an alternative form of immigrant economic adaptation. American Sociological Review 2(67): 278-298.

Rapoport RN (1970). Three dilemmas in action research. Human Relations 23(6): 499 513.

Rickert H (1929) Zur Lehre von der Defintion. (On the doctrine of definition). (3. Aufl.) Tübingen: J.C.B. Mohr.

Santamaria-Alvarez SM, Munoz-Castro DC, Sarmiento-Gonzalez MA, Marin-Zapata SI (2018) Fragmented networks and transnational entrepreneurship: building strategies to prosper in challenging surroundings. Journal of International Enterpreneurship 16(2) 244-257.

Schumpeter JA, Opie R, Elliott JE (1911) The theory of economic development: an inquiry into profits, capital, credit, interest, and the business cycle, New Brunswick (USA) and London, Transaction Publishers

Scott S, Venkatarman S (2000) The promise of entrepreneurship as a field of research. Academy of Management Review 25(1): 217-226.

Sleuwegen L, Onkelinx J (2014) International commitment, post-entry growth and survival of international new ventures. Journal of Business Venturing 29(1): 106-120.

Sternad D, Hartlieb E, Stromberger M (2018) Internationalisierung von Start-ups. (Internationalizing of start-ups). Berlin: Springer Gabler.

Stevenson HH (2006) A perspective on entrepreneurship. Brighton (UK): Harvard Business Review.

Susman GI, Evered RD (1978) An assessment of the scientific merits of action research. Administrative Science Quarterly 4(23): 582-586.

Tödtmann C (2018) Warum sich der Mittelstand mit Big Data so schwertut. Studie zur Digitalisierung. (Why medium-sized businesses have such a hard time with Big Data. Study on digitization). (Wirtschaftswoche (wiwo.de). Retrieved from: https://bit .ly/3bAykw2. [Accessed 7 September 2020.]

UNESCO (Hg.) (2017) Trans-nationalism. Retrieved from: http://www.unesco.org/new/ en/social-and-human-sciences/themes/international-migration/glossary/trans-nationa lism/. [Accessed 7 September 2020.]

Wenhong C, Tan J (2009) Understanding transnational entrepreneurship through a network lens: theoretical and methodological considerations. Entrepreneurship Theory and Practice: 26(4): 1079-1091.

Zapata-Barrero R, Rezaei S (2020) Diaspora governance and transnational entrepreneurship: the rise of an emerging social global pattern in migration studies. Journal of Ethnic and Migration Studies 46(10): 1959-1973. 